\title{
Inter-relationship among obesity cardiorespiratory fitness, and body image attitude among menopausal women in Oyo state Nigeria
}

\author{
Omoyemi O. Ogwumike ${ }^{1,2}$, Ololade I. Salam ${ }^{1,3}$
}

\begin{abstract}
Introduction Abdominal obesity is the accumulation of excess adipose tissue in the abdomen. Hormonal changes in menopausal women may lead to physical inactivity which results in decreased cardiorespiratory fitness and increase in incidence of obesity. Cardiorespiratory fitness is one of the strongest predictors of cardiovascular health and longevity and a useful health indicator. The interrelationship among abdominal obesity, cardiorespiratory fitness and body image attitude among menopausal women was investigated in this study.

Method A cross-sectional survey method was adopted, using purposive sampling to recruit women from Iseyin Local Government Area, Oyo State, Nigeria. Premenopausal, perimenopausal and postmenopausal women had their abdominal obesity, cardiorespiratory fitness and body image attitude assessed using waist circumference, six minute-walk test and multidimensional body-self relations questionnaire (MBSRQ) respectively. Data were analysed using descriptive and inferential statistics with $\alpha=0.05$.

Results Participants comprised 381 women aged $47.1 \pm 8.6$ years, they had low mean estimated maximum oxygen consumption of $10.81 \pm 1.77 \mathrm{ml} / \mathrm{kg} / \mathrm{min}$. The postmenopausal women had the highest median score of abdominal obesity of $96.0(20.0) \mathrm{cm}$. A positive and significant weak correlation of abdominal obesity with cardiorespiratory fitness was observed among the premenopausal ( $r=0.156 ; p=0.050$ ) women while negative and non-significant correlations were observed in both the perimenopausal and postmenopausal groups. Cardiorespiratory fitness and abdominal obesity exhibited varied correlations with body image attitude variables of menopausal women.

Conclusion Cardiorespiratory fitness and abdominal obesity were somewhat indirectly correlated in the older menopausal women. They also exhibited variable correlations toward body image.
\end{abstract}

\section{About the AUTHORS}

1 Department of Physiotherapy, College of Medicine University of Ibadan, Nigeria 2 Department of Physiotherapy, University College Hospital Ibadan, Nigeria 3 Federal Ministry of Health, Hospital Services Department Abuja, Nigeria

Contact: Omoyemi O. Ogwumike yemfide@yahoo.com

Clin Health Promot 2019; 9:40-47

\section{Introduction}

Abdominal obesity is the accumulation of excess adipose tissue in the abdomen (1). Obesity and overweight occur when there is an imbalance between energy intake and expenditure. It is the most prevalent nutritional disorder in which there is excessive storage of energy in the form of fat (2). Women with abdominal obesity have a higher incidence of cardiovascular disease (CVD) morbidity and mortality compared to men (3). Studies have shown that different stages of reproductive life of women, such as menarche, pregnancy, and menopausal transition, are associated with unfavourable changes in body composition, abdominal fat deposition and general health outcomes $(4,5)$.
Cardiorespiratory fitness (CRF) is a health-related component of physical fitness and it is the ability of the circulatory, respiratory, and muscular systems to supply oxygen during sustained physical activity (6). Health-related physical fitness can be defined as the ability to perform daily activities with vigour and energy that leads to a lower risk of diseases or chronic degenerative conditions associated with low levels of physical activity. Physical inactivity leads to low CRF and has been linked to a high prevalence of overweight and obesity among women (7).

Abdominal obesity is associated with increased aortic stiffness, an independent predictor of CVD events (8). It is also 
strongly associated with traditional CVD risk factors such as hypertension, dyslipidaemia, and impaired glucose metabolism (9). For women, fluctuations in sex hormones at different stages of reproductive life, such as menarche, pregnancy, and menopause transition may play a role in the accumulation of adipose tissue in the abdomen (4) and this may create a great concern for women about their body image.

Body image is conceived as a person's attitudinal dispositions toward the physical self (10). As attitudes, these dispositions include evaluative, cognitive, and behavioural components. Moreover, the physical self encompasses not only physical appearance but also the body's competence or "fitness" and its biological integrity or health/illness' (11). Body image is a subjective picture of physical appearance established both by self-observation and by noting the reactions of others. It is also a subjective and multidimensional construct to all kinds of distortions from internal elements like emotions, moods, early experiences and attitudes of parents (11). Body image can either be positive or negative (12). Positive body image or healthy body image is marked by realistic imagination and acceptance of an individual's body structure (13). In contrast, negative body image or unhealthy body image comprises shame, embarrassment, disappointment or anxiety about how the individual looks. People who are categorized into this group may not have a realistic understanding of their body structures (13). It is noteworthy that socio-cultural differences exist in body image attitudes among different populations around the world; for example in African societies, being fat is considered a sign of 'good living' (14). This is in contrast to what is obtainable in North America, where attractiveness is associated with being thin for women, while black males prefer a heavier female body size than their white counterparts (13). Several investigators have found distortions in the attitudes of some individuals, especially women, towards their body image, including overestimation of body size and negative attitudes towards the body (13).

The loss of ovarian hormones in menopause results in marked biochemical, physiological and structural changes that alter the overall health status of a woman with resultant concern about body image and possibly cardiorespiratory fitness. Menopause is inevitable and literature supports menopause-related decline in VO2 max at a rate of approximately $10 \%$ per decade from age 30 years $(15,16)$.

According to the International Menopause Society (IMS), menopausal women are usually considered in three phases of life which include: the premenopause stage, this refers to the whole of the reproductive period prior to menopause; peri-menopause, which refers to the period immediately prior to menopause, when the clinical features of approaching menopause commence and the first year after menopause; and the post-menopause phase, which is the period starting from the final menstrual period (17).

Studies on overweight and obesity have been reported among different groups of Nigerians $(18,19,20)$ but researches focusing on body image and each of cardiorespiratory fitness and abdominal obesity among Nigerian women seem to be scarce. Though, similar researches have been conducted outside Africa $(21,22)$, their findings may not be generalised to Nigerian women because body image is a psychological phenomenon and can be influenced by culture, lifestyle and value system (23).

It may therefore be of interest to investigate: (1) If there may be any likely differences in cardiorespiratory fitness, abdominal obesity and attitude toward body image among women in the three menopausal groups; (2) If there would be possible interrelationships among cardiorespiratory fitness, abdominal obesity and body image attitude among women in the three menopausal categories.

\section{Methods \\ Study participants}

Using the purposive sampling method, apparently healthy women aged between 30 and 69 years were recruited into this cross-sectional survey study from February to July 2016. The study population was from Iseyin, a semi-urban area in Oyo-state Nigeria. A sample size calculation was made using the Cochrane formula $\mathrm{N}=\mathrm{Z}^{2} \mathrm{pq} / \mathrm{d}^{2}$ and the proportion used was that of women who had abdominal obesity from the study of Ijezie et al. 2013 (24). Ethical approval was obtained from UI/ UCH Ethical Review Committee before the commencement of the study. Informed consent was also obtained from the participants who were workers in various establishments and institutions in Iseyin Local Government Area of Oyo State, Nigeria. Permission to conduct the study was also obtained from the various managements of the institutions where data was collected.

\section{Procedure for data collection}

Each prospective participant had her heart rate and blood pressure assessed through auscultation method after a 15-minutes rest. Those with resting blood pressure $>160 / 100 \mathrm{mmHg}$ were excluded from the study. A 13-item bio-data form was used to retrieve socio-demographic information which included age, sex, marital 
status, educational level, occupation, personal income, and other information. Educational level was assessed in three categories: primary, secondary, and tertiary. Those with tertiary education were those who had post-secondary education, such as university degree holders, polytechnic, or college of education higher degree qualifications. Personal income was assessed in four categories based on the 2011 Federal Government of Nigeria's minimum wage classification system of 18,000 naira per month (about US\$113). Individuals with 18,000 naira wages per month were classified under low income; those with middle, moderate, and high incomes were those who earned three, five and greater than seven times the minimum wage respectively (25). Menstrual cycle status information was also obtained in order to classify the women into appropriate menopausal groups $(26,27)$.

\section{Assessment of cardiorespiratory fitness}

Cardiorespiratory fitness was assessed by asking each participant to do a six-minute walk test (6MWT) with a self-paced speed on a 30 metre marked level ground hallway. The participant was encouraged during the walk as standardised. Exhaustion was noted as when the participant was no longer able to continue walking or complained of chest pain, light-headedness, intolerable dyspnoea, leg cramps or muscle fatigue. On completion of the test, the participant immediately sat down and pulse rate, rating of perceived exertion using the modified Borg index and the 6MW distance were measured and the participant's speed (metres/min) was calculated. The VO2max was calculated using the American College of Sport Medicine - ACSM, $(28,29)$ prediction of maximum oxygen consumption during level walking. The calculation to compute the VO2max for each participant was done as follows:

$\mathrm{VO}_{2} \max =$ Speed $(\mathrm{m} / \mathrm{min}) \times 0.1 \mathrm{ml} \mathrm{O}_{2} / \mathrm{kg}+3.5 \mathrm{ml} \mathrm{O}_{2} / \mathrm{kg} / \mathrm{min}$

\section{Assessment of abdominal obesity}

The participant was asked to stand by the wall in an erect position. A tape measure was then put round the waist with the iliac crest as the point of reference/landmark. Care was taken not to stretch the tape and measurement was approximated to the nearest centimetre (30). According to the National Heart, Lung and Blood Institute (NHLBI), (31) women with a waist circumference of $\leq 88 \mathrm{~cm}$ were classified as having normal waist circumference while those with waist circumference $>$ $88 \mathrm{~cm}$ were classified as obese.

\section{Procedure}

A cross-sectional design and survey method with physical measurement of participants' health indicators was used for this study.

\section{Assessment of body image attitude}

The Multidimensional Body-Self Relations Questionnaire (MBSRQ) developed by Cash (11) for the assessment of body image attitude of participants was hand-distributed and self-administered. The 69-item scale was classified into nine subscale items were rated on a five-point Likert scale: Appearance Evaluation, Fitness Evaluation, Health Evaluation, Appearance Orientation, Fitness Orientation, Health Orientation, Overweight Preoccupation, Self-Classified Weight and Body Area Satisfaction Scale. Some items evaluated agreement while others assessed frequency or satisfaction. The MBSRQ generally has good psychometric properties with internal consistencies ranging from 0.70 to 0.89 and one-month test retest reliability ranging from 0.74 to 0.91 . The Cronbach's alpha coefficients of the subscales ranged from 0.77 to 0.88 (32). A previous study using the MBSRQ in the Nigerian female population yielded a Cronbach's alpha of 0.78 indicating that the instrument is a reliable tool in the Nigerian setting (33). The overall score of each of the subscales of the MBSRQ is 5. Participants with scores between 1 and 2.5 had low attitudinal disposition towards their body image, while participants who scored between 2.6 and 5 had moderate to high attitudinal disposition towards their body image (10).

\section{Data analysis}

Continuous variables were summarised using median and interquartile ranges while categorical variables were summarised using frequencies and percentages. The non-parametric Kruskal Wallis test was employed to analyse the relationship between CRF and abdominal obesity of each of the three menopausal groups. The attitudinal disposition of participants toward body image was evaluated and determined based on the median score of individual participants on every domain of the MBSRQ Cash (11). In addition, Spearman's correlation analysis was used to analyse the relationship among abdominal obesity, cardiorespiratory fitness and body image attitude variables of menopausal women and $\alpha$ was set at 0.05 .

\section{Results}

\section{Characteristics of participants}

A total of 430 women were recruited. 31 did not complete participation after the initial assessment, 18 did not fill their questionnaires properly and were withdrawn from the study. 381 completed participation and had their questionnaires correctly filled. This gave a response rate of $88.6 \%$. Participants were all of the Yoruba tribe in South-western Nigeria. The mean age was $47.1 \pm 8.6$ years with the age range 30 to 69 years. The 


\section{Research and Best Practice}

Table 1. Characteristics of participants in the study $(\mathrm{N}=381)$

\begin{tabular}{|c|c|c|}
\hline Variable & $\mathrm{n}$ & $\%$ \\
\hline \multicolumn{3}{|l|}{ Age group (years) } \\
\hline $30-39$ & 78 & 20.5 \\
\hline $40-49$ & 135 & 35.4 \\
\hline $50-59$ & 138 & 36.2 \\
\hline $60-69$ & 30 & 7.9 \\
\hline \multicolumn{3}{|l|}{ Marital Status } \\
\hline Married & 342 & 89.7 \\
\hline Not Married & 39 & 10.3 \\
\hline \multicolumn{3}{|l|}{ Education } \\
\hline Primary & 21 & 5.5 \\
\hline Secondary & 18 & 4.7 \\
\hline Tertiary & 342 & 89.8 \\
\hline \multicolumn{3}{|l|}{ Employment } \\
\hline Government employed & 324 & 85 \\
\hline Self-employed & 57 & 15 \\
\hline \multicolumn{3}{|l|}{ Personal Income } \\
\hline Low & 171 & 44.9 \\
\hline Middle & 168 & 44.1 \\
\hline Moderate & 36 & 9.4 \\
\hline High & 6 & 1.6 \\
\hline \multicolumn{3}{|l|}{ Menopausal Group } \\
\hline Premenopause & 159 & 41.7 \\
\hline Perimenopause & 63 & 16.5 \\
\hline Postmenopause & 159 & 41.7 \\
\hline \multicolumn{3}{|l|}{ Waist Circumference } \\
\hline Normal $(\leq 88 \mathrm{~cm})$ & 138 & 36.2 \\
\hline Obese ( $\geq 88 \mathrm{~cm})$ & 243 & 63.8 \\
\hline
\end{tabular}

$$
\text { Key: }
$$

$\mathrm{N}=$ Total number of participants

$\mathrm{n}=$ Frequency

$\%=$ Percentage occurrence majority of the women, 342 (89.8\%), were married, had tertiary education and were all employed, with 324 (85\%) in paid government employment (Table 1).

\section{Perceived health status of participants}

Table 2 shows the perceived health status of participants with the majority of the women 282 (74.0\%) reporting their health status as good with 135 (84.9) belonging to the premenopausal category.

\section{Analysis of cardiorespiratory fitness and ab- dominal obesity}

The result of the Kruskal Wallis test is shown in Table 3. Of the three menopausal groups, the postmenopausal women showed the greatest median score for abdominal obesity [96 (20)], with the perimenopausal [94 (11)] and the premenopausal [9o (16)] also in the high end. Significant differences existed only in the abdominal obesity index $(\mathrm{p}=0.001)$ while no significant difference existed in CRF among the three women groups. In addition, a positive and significant weak correlation of abdominal obesity with cardiorespiratory fitness was observed among the premenopausal women $(\mathrm{r}=0.156$; $\mathrm{p}=0.050$ ) while negative and non-significant correlations were observed in both the perimenopausal and postmenopausal groups.

\section{Analysis of the body image attitude variables of the menopausal women}

Table 4 presents the median scores of the participants in the nine domains of the MBSRQ. Results showed that all participants irrespective of their menopausal category had moderate to high attitudinal disposition

Table 2. Health profile of participants in the study $\mathrm{N}=(381)$

\begin{tabular}{|c|c|c|c|c|c|c|c|c|}
\hline \multirow[b]{3}{*}{ Variable } & \multicolumn{6}{|c|}{ Menopausal group } & & \\
\hline & \multicolumn{2}{|c|}{ Premenopause } & \multicolumn{2}{|c|}{ Perimenopause } & \multicolumn{2}{|c|}{ Postmenopause } & \multicolumn{2}{|c|}{ Total } \\
\hline & $\mathrm{n}$ & (\%) & $\mathrm{n}$ & $(\%)$ & $\mathrm{n}$ & $(\%)$ & $\mathrm{n}$ & (\%) \\
\hline \multicolumn{9}{|l|}{ Perceived Health Status } \\
\hline Good & 135 & $(84.9)$ & 60 & $(95.2)$ & 87 & $(54.7)$ & 282 & $(74.0)$ \\
\hline Fair & 18 & $(11.3)$ & 3 & $(4.8)$ & 69 & $(43.4)$ & 90 & $(23.6)$ \\
\hline Poor & 6 & $(3.8)$ & 0 & $(0.0)$ & 3 & $(1.89)$ & 9 & $(2.4)$ \\
\hline Total & 159 & $(100)$ & 63 & $(100)$ & 159 & $(100)$ & 381 & $(100)$ \\
\hline \multicolumn{9}{|l|}{ Health Problems } \\
\hline None & 145 & $(91.2)$ & 55 & $(87.3)$ & 69 & $(43.4)$ & 269 & $(70.6)$ \\
\hline Musculoskeletal Pain & 5 & (3.1) & 4 & $(6.3)$ & 61 & $(38.4)$ & 70 & $(18.4)$ \\
\hline Hypertension/Diabetes & 2 & $(1.3)$ & 2 & $(3.2)$ & 15 & $(9.4)$ & 19 & $(5.0)$ \\
\hline Malaria/Others & 7 & $(4.4)$ & 2 & $(3.2)$ & 14 & $(8.8)$ & 23 & $(6.0)$ \\
\hline Total & 159 & (100) & 63 & $(100)$ & 159 & $(100)$ & 381 & (100) \\
\hline
\end{tabular}

Key:

$\mathrm{N}=$ Total number of participants

$\mathrm{n}=$ Frequency

$\%=$ Percentage occurrence 


\section{Research and Best Practice}

Tabel 3. Correlation analysis between cardiorespiratory fitness and abdominal obesity $(\mathrm{WC})$ in the menopausal group of women in the study $(\mathrm{N}=381$ )

\begin{tabular}{|c|c|c|c|c|c|c|}
\hline \multirow[t]{2}{*}{ Participant group } & \multicolumn{2}{|c|}{ CRF level $\left(\mathrm{VO}_{2} \max \right)$} & \multicolumn{2}{|c|}{ Abdominal Obesity Index } & \multirow[b]{2}{*}{$r$} & \multirow[b]{2}{*}{$\mathrm{p}$-value } \\
\hline & Median & $(\mathrm{IQR})$ & Median & $(\mathrm{IQR})$ & & \\
\hline Premenopause & 13.70 & $(20.98)$ & 90.0 & $(16.0)$ & 0.156 & 0.050 \\
\hline Perimenopause & 13.48 & $(20.94)$ & 94.0 & $(11.0)$ & -0.030 & 0.815 \\
\hline Postmenopause & 14.13 & $(24.98)$ & 96.0 & $(20.0)$ & -0.005 & 0.951 \\
\hline K & 2.29 & & 14.05 & & & \\
\hline$p$-value & 0.319 & & 0.001 & & & \\
\hline \multicolumn{7}{|l|}{ Key: } \\
\hline $\mathrm{N}=$ Total number of participants & \multicolumn{6}{|c|}{$r=$ Spearman rho } \\
\hline $\mathrm{CRF}=$ Cardiorespiratory fitness & \multicolumn{6}{|c|}{$\mathrm{K}=$ Kruskal Wallis value } \\
\hline
\end{tabular}

$\mathrm{IQR}=$ Inter quartile range

towards their body image and were satisfied with their body as they all had scores well above 2.5. A Kruskal Wallis test of body image variables of the women in the three menopausal groups revealed that appearance evaluation, appearance orientation, self-classified weight and body area satisfaction were significantly different $(\mathrm{p}<0.001)$ while the rest were not.

Relationship among cardiorespiratory fitness, abdominal obesity and body image attitude variables of the menopausal women

In Table 5, Spearman's correlation analysis was used to test correlations among cardiorespiratory fitness and abdominal obesity with the body image attitude variables of the participants. Results showed that there were differences in correlation in each of the variables in the different menopausal groups. Negatively significant correlations were observed when abdominal obe- sity and cardiorespiratory fitness were correlated with fitness evaluation $[\mathrm{r}=-0.216 ; \mathrm{p}=0.01]$, health evaluation $[\mathrm{r}=-0.303, \mathrm{p}=0.000]$, fitness orientation $[\mathrm{r}=-0.203$, $\mathrm{p}=0.01]$ and health orientation $[\mathrm{r}=-0.160 ; \mathrm{p}=0.04]$, with a positive significant correlation with self-classified weight $[\mathrm{r}=0.233 ; \mathrm{p}=0.003]$ among postmenopausal women. For perimenopausal women, positive significant correlations were observed for health evaluation $[\mathrm{r}=0.265 ; \mathrm{p}=0.004]$, appearance orientation $[\mathrm{r}=0.383$; $\mathrm{p}=0.002]$, health orientation $[\mathrm{r}=0.397 ; \mathrm{p}=0.001]$, overweight preoccupation $[\mathrm{r}=0.384 ; \mathrm{p}=0.002]$ and self-classified weight $[\mathrm{r}=0.556 ; \mathrm{p}=0.000]$, while negative significant correlations were observed in fitness orientation $[\mathrm{r}=-0.290 ; \mathrm{p}=0.021]$ and body area satisfaction. For premenopausal women, positive significant correlations were observed in overweight preoccupation $[\mathrm{r}=0.185 ; \mathrm{p}=0.003]$ and self-classified weight [r=0.372; $\mathrm{p}=0.000]$.

Table 4. Kruskal Wallis analysis of body image attitude variables of menopausal women in the study

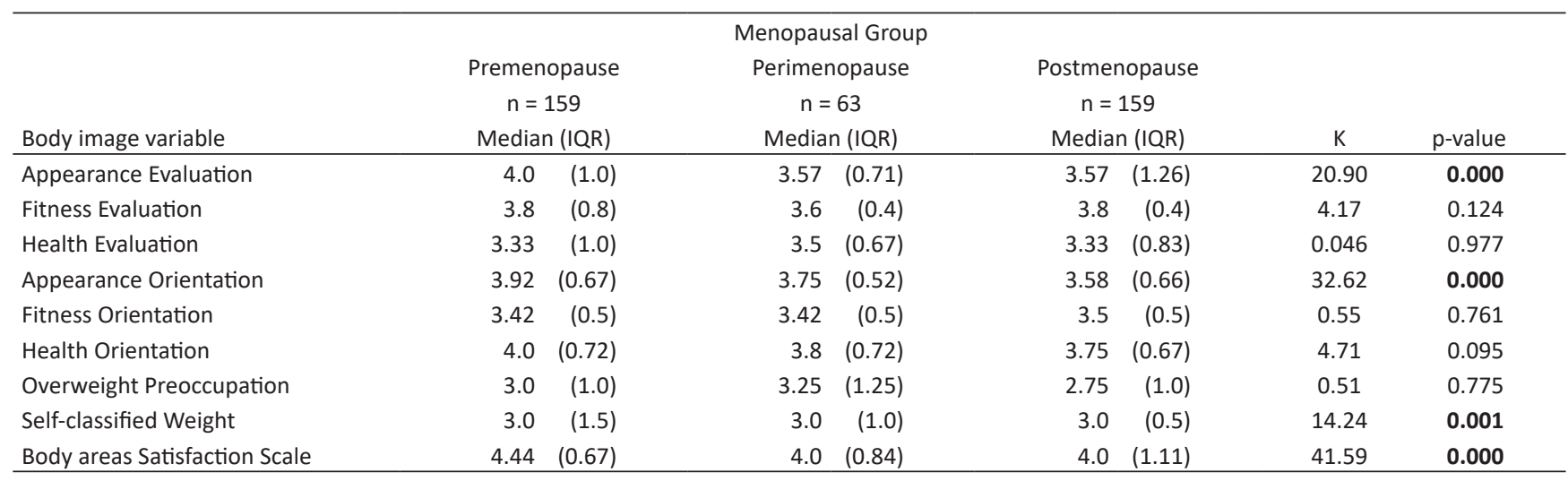

Key:

$\mathrm{n}=$ frequency of occurrence

$\mathrm{IQR}=$ Inter quartile range

$r=$ Spearman rho 
Table 5. Correlation analysis among cardiorespiratory fitness, abdominal obesity (WC) and body image attitude of menopausal women in the study

\begin{tabular}{|c|c|c|c|c|c|c|c|}
\hline \multirow[b]{3}{*}{ Body image variable } & & \multicolumn{6}{|c|}{ Menopausal groups } \\
\hline & & \multicolumn{2}{|c|}{ Premenopause } & \multicolumn{2}{|c|}{ Perimenopause } & \multicolumn{2}{|c|}{ Postmenopause } \\
\hline & & $\mathrm{VO}_{2} \mathrm{Max}$ & $\mathrm{AOI}$ & $\mathrm{VO}_{2} \mathrm{Max}$ & $\mathrm{AOI}$ & $\mathrm{VO}_{2} \mathrm{Max}$ & $\mathrm{AOI}$ \\
\hline Appearance evaluation & $\mathrm{p}$-value & 0.631 & 0.135 & 0.865 & 0.531 & 0.914 & 0.473 \\
\hline \multirow[t]{2}{*}{ Fitness evaluation } & $r$ & -0.090 & -0.121 & 0.006 & -0.056 & -0.120 & -0.022 \\
\hline & $\mathrm{p}$-value & 0.257 & 0.129 & 0.962 & 0.663 & 0.130 & 0.006 \\
\hline \multirow[t]{2}{*}{ Health evaluation } & $r$ & 0.006 & -0.120 & -0.058 & 0.265 & 0.035 & -0.303 \\
\hline & p-value & 0.940 & 0.133 & 0.653 & 0.036 & 0.009 & 0.057 \\
\hline \multirow[t]{2}{*}{ Appearance orientation } & $r$ & -0.091 & -0.112 & 0.012 & 0.383 & -0.159 & 0.011 \\
\hline & $\mathrm{p}$-value & 0.255 & 0.159 & 0.927 & 0.002 & 0.045 & 0.891 \\
\hline Fitness orientation & $r$ & -0.062 & -0.036 & -0.290 & 0.067 & -0.059 & -0.203 \\
\hline \multirow[t]{2}{*}{ Health orientation } & $r$ & -0.021 & -0.141 & -0.195 & 0.397 & 0.000 & -0.160 \\
\hline & p-value & 0.793 & 0.077 & 0.126 & 0.001 & 0.998 & 0.044 \\
\hline \multirow[t]{2}{*}{ Overweight preoccupation } & $r$ & 0.048 & 0.185 & 0.046 & 0.384 & 0.141 & 0.150 \\
\hline & p-value & 0.552 & 0.019 & 0.720 & 0.002 & 0.076 & 0.059 \\
\hline \multirow[t]{2}{*}{ Self-classified weight } & r & -0.040 & 0.372 & 0.072 & 0.556 & -0.062 & 0.233 \\
\hline & $\mathrm{p}$-value & 0.618 & 0.000 & 0.577 & 0.000 & 0.435 & 0.003 \\
\hline \multirow[t]{2}{*}{ Body areas satisfaction scale } & $r$ & -0.017 & -0.181 & 0.041 & -0.436 & 0.017 & -0.073 \\
\hline & p-value & 0.835 & 0.022 & 0.751 & 0.000 & 0.833 & 0.363 \\
\hline
\end{tabular}

Key:

$r=$ Spearman rho

$\mathrm{VO}_{2} \mathrm{Max}=$ Cardiorespiratory fitness

$\mathrm{AOI}=$ Abdominal Obesity Index

\section{Discussion}

\section{Characteristics of participants}

This study investigated interrelationship among cardiorespiratory fitness, abdominal obesity and body image attitude among menopausal women. Most of the participants had tertiary education and were mostly government employed. This may be due to the study population which consisted of individuals recruited from government/civil establishments. Such workers are required to have at least post-secondary school education before being considered for employment. The majority of the participants were married.

\section{Perceived health status of participants}

In this study, it was observed that the majority of the menopausal women perceived their health status to be good. Postmenopausal women however mostly reported musculoskeletal pain, hypertension and diabetes as their health problems. This observation is in line with those of previous studies on menopausal women, indicating that older menopausal women experience greater pain symptoms and other health problems than pre-

menopausal women $(33,34)$.

\section{Cardiorespiratory fitness level in menopausal women in this study}

Cardiorespiratory fitness of the majority of participants in this study was poor. The mean 6-minute walk distance (6MWD) in this study was $440.76 \pm 105.68$ $\mathrm{m}$ and estimated maximum oxygen consumption was $10.81 \pm 1.77 \mathrm{ml} / \mathrm{kg} / \mathrm{min}$. This finding is in contrast to that of Stevens et al., (35) who reported higher mean 6MWD and estimated maximum oxygen consumption of $630 \mathrm{ml}$ and $17.5 \mathrm{ml} / \mathrm{kg} / \mathrm{min}$ respectively among healthy adults. However, the mean predicted $\mathrm{VO}_{2} \max$ found in this study was lower than the mean predicted $\mathrm{VO}_{2}$ max reported by the American College of Sport Medicine (36) for normal and sedentary healthy individuals ranging from $14.0-38.4(\mathrm{ml} / \mathrm{kg} / \mathrm{min})$. This indicates that many of the participants were probably not involved in sufficient physical activity to improve their cardiorespiratory fitness as they needed moderate to vigorous intensity activity to improve their health status. They could therefore have been prone to sedentary health problems such as: cardiovascular diseases, type 2 diabetes, obesity, high blood pressure, osteoporo- 


\section{Research and Best Practice}

sis, depression and anxiety as identified by the United States Department of Health and Human Services (37). A probable reason for this finding could be that the majority of the participants in this study were civil servants with predominantly sedentary attitude.

\section{Relationship between abdominal obesity and cardiorespiratory fitness level among meno- pausal women in this study}

The majority of the participants in this study were obese, and the postmenopausal women had the highest median score for abdominal obesity. This is not an unusual finding as previous studies have reported weight gain during the menopausal transition (4). Also, Peppa et al., (38) reported increased central fat deposition, decreased peripheral fat mass accumulation and ectopic fat storage in postmenopausal women. In addition, the negative correlation of cardiorespiratory fitness with abdominal obesity in perimenopausal and postmenopausal women, even though statistically non-significant, may be of important clinical relevance. This is because accumulation of abdominal adipose tissue has been observed to be associated with aging and sedentariness, which in turn leads to poor cardiorespiratory fitness in women at menopause $(4,39)$. The depleting oestrogen levels induce lower metabolic rate, reduced physical energy expenditure and an increase in fat mass and abdominal adipose tissue accumulation (40).

\section{Relationship among cardiorespiratory fitness, abdominal obesity and body image attitude of menopausal women}

The results of this study revealed that all the participants had positive attitudinal disposition towards body image, irrespective of their menopausal category, as indicated by the median scores on the various subscales of the MBSRQ. However, it was noted that premenopausal women had the highest median scores in appearance evaluation, appearance orientation, health orientation and body areas satisfaction compared to perimenopausal and postmenopausal women. This showed that premenopausal women were most satisfied with certain areas of their body compared to their perimenopausal and postmenopausal counterparts. This study also revealed that all the participants had relatively similar scores in the domain of fitness evaluation, health evaluation and self-classified weight, irrespective of their menopausal status. This means all the participants had high feelings about their physical health, therefore, the majority of them felt their bodies were in good health (11). Furthermore, the fact that cardiorespiratory and abdominal obesity exhibited varied correlations with most body image attitudinal variables of menopausal women possibly reflected variability in the preoccupation of menopausal women with these body image variables in view of their varied cardiorespiratory and body composition states. For instance, fitness evaluation and health evaluation were significantly negatively correlated. For fitness evaluation, the clinical implication here could be that participants were not actually as physically fit as they thought based on their prevalent physical performance and energy expenditure. It is also noteworthy that all participants in this study had lower cardiorespiratory fitness compared to that recommended for maintenance of optimum healthy living in adults, however, the premenopausal and perimenopausal women were probably more involved in physical activity behaviour, even though at insufficient amounts, relative to their postmenopausal counterparts.

\section{Limitations to the study}

The method of recruitment of participants into this study, viz purposive sampling technique, and the population may pose some selective bias. This is because there was the need for the participants to comprehend the instructions and instruments employed in the study, hence women who were mostly workers in government workplaces were recruited. In view of this, the results obtained may not be representative of the uneducated and poorer social class in the Nigerian populace. The use of the Multidimensional Body Self-relations Questionnaire in this study may be associated with expectation bias in the selection of item statements. These may, to a certain extent, limit the generalisability of the findings in this study.

\section{Conclusion}

Cardiorespiratory fitness and abdominal obesity were indirectly correlated in older menopausal women. They also exhibited variable correlation toward body image. Menopausal women are enjoined to improve their physical activity behaviour in order to achieve the recommended level of cardiorespiratory fitness and reduce adipose tissue accumulation in order to enhance health benefits.

\section{Authorship Credit}

Conception and Design: OO

Acquisition of Data: OS

Analysis and Interpretation of Data: OO, OS

Drafting, Revising and Final Approval of the Article: OO, OS

\section{Conflicts of interests}

None declared. 


\section{References}

1. Lesser IA, Dick TJM, Guenette JA, Hoogbruin A, Mackey DC, Singer J, Lear SA. The association between cardiorespiratory fitness and abdominal adiposity in postmenopausal, physically inactive South Asian women. Prev Med Rep 2. 2015; 783-787.

2. World Health Organization (WHO). Obesity and overweight. 2005. http://www.who.int, (Retrieved March 4, 2009).

3. Flint AJ, Rexrode KM, Hu FB. Body mass index, waist circumference, and risk of coronary heart disease: a prospective study among men and women. Obes Res Clin Pract. 2010;4:e171-e181.

4. Davis SR, Castelo-Branco C, Chedraui P, Lumsden MA, Nappi RE, Shah D, Villaseca P. Understanding weight gain at menopause. Climacteric. 2012;15:419-429

5. Haslam DW, James WP. Obesity. Lancet. 2005; 366 (9492): 1197209.

6. Lee IM RK, Cook NR, Manson JE, Buring JE. Physical activity and coronary heart disease in women. J Am Med Assoc. 2010; 285:14471454 .

7. Lyerly GW, Sui X, Lavie CJ, Church TS, Hand GA, Blair SN. The association between cardiorespiratory fitness and risk of all-cause mortality among women with impaired fasting glucose or undiagnosed diabetes mellitus. Mayo Clin Proc. 2009; 84:780-786.

8. Wildman RP, Mackey RH, Bostom A, Thompson T, Sutton-Tyrrell K. Measures of obesity are associated with vascular stiffness in young and older adults. Hypertension. 2003; 42:468-473.

9. Recio-Rodriguez JI, Gomez-Marcos MA, Patino-Alonso MC, Agudo-Conde C, Rodriguez-Sanchez E, Garcia-Ortiz L. 2012. Abdominal obesity vs general obesity for identifying arterial stiffness, subclinical atherosclerosis and wave reflection in healthy, diabetics and hypertensives. BMC Cardiovasc Disord; 12:3.

10. Cash T Pruzinsky, T. Body image: A handbook of theory, research, and clinical practice. New York: Guilford Press; 2002.

11. Cash TF. Body image: Past, present, and future. Body Image. 2004; 1(1): 1-5.

12. Esnaola I, Arantzazu R, Alfredo G. Body dissatisfaction and perceived sociocultural pressures: gender and age differences. Salud Mental. 2010; 33(1):21-29.

13. Reynaga-Abiko G. Body image. In: Stange MZ, Oyster CL, Sloan JE, editors. Encyclopedia of women in today's world. California: SAGE Publications. 2011; 170-4.

14. Nkwoka IJ, Egua MO, Abdullahi M, Sabiu A, Mohammed AI. Overweight and obesity among staff of Usmanu Danfodiyo University, Sokoto, Nigeria. Educ Res. 2014; 5:290-5.

15. Hawkins SA, Wiswell R. Rate and mechanism of maximum oxygen consumption decline with aging: implications for exercise training. Sports Medicine. 2003; 33(12): 877-888.

16. Hollenberg M, Yang J, Haight T J, Tager I B. Longitudinal changes in aerobic capacity: implications for concepts of aging. Journals of Gerontology, Series A: Biological Sciences and Medical Sciences. 2006; 61 (8), 851-858.

17. Utian WH. The International Menopause Society menopause-related terminology definitions. Climacteric.1999 Dec; 2(4):284-6.

18. Abubakhari AR, Bhopal RS. Systematic review on the prevalence of diabetes overweight/obesity and physical inactivity in Ghanaians and Nigerians. Public Health. 2008; 122(2): 173-182.

19. Siminialayi IM, Emem-Chioma PC, Dapper DV. The prevalence of obesity as indicated by BMI and waist circumference among Nigerian adults attending Family Medicine clinics as outpatients in Rivers State. Nigerian Journal of Medicine. 2008; 17(3):340-345.

20. Kolawole WW, Mahmoud US, Bashir OY, Maruf G, Akeem G, Mahmoud IY. Defining obesity using three anthropometric parameters, being components of two diagnostic criteria, amongst Nigerian women. International Archive of Medicine. 2011; 4(10): 4-10.
21. Alwan H, Viswanathan B, Paccaud F, Bovet P. Is accurate perception of body image associated with appropriate weight-control behaviour among adolescents of the Seychelles. Journal of Obesity. 2011; 10 (1155): 1-8.

22. Yahia N, El-Ghazale H, Achkar A, Rizk S. Dieting practices and body image perception among Lebanese university students. Asia Pacific J Clin Nutr. 2011; 20(1):21-8.

23. Cash TF, Pruzinski T. Body image, a handbook of theory, research and clinical practice. Guilford press New York 1990.

24. Ijezie IC, Chuku A, Ogah OS. Prevalence of abdominal obesity in Abia State, Nigeria: results of a population-based house to house survey. Diabetes, Metabolic Syndrome and Obesity: Targets and Therapy 2013; 6: 285-291.

25. Ogwumike OO. Adeniyi AF, Orogbemi OO. Physical activity level of postmenopausal women in Nigeria: Association with self-rated health status, overall obesity and abdominal obesity. Women and $\mathrm{He}-$ alth. 2016; 56(5): 487-501

26. Daley AH, Stokes-Lampard S, Wilson M, Rees A, Roalfe C, Mac Arthur What women want: exercise preferences of menopausal women. Maturitas. 2011; 68: 174-78.

27. Ogwumike OO, Adeniyi AF, Ukpe PU. Body image attitudes and physical activity level of premenopausal and perimenopausal women in Nigeria. J Behav Health. 2016; 15 (2): 55-59.

28. American College of Sport Medicine. Guidelines for Graded Exercise Testing and Exercise Perception. ( Philadelphia: Lea and Fabiyer; 1995.

29. Adedoyin RA, Adeyanju SA, Balogun, MO, Adebayo RA, Akintomide AO, Akinwusi PO. Prediction of functional capacity during six-minute walk among patients with chronic heart failure. Niger $\mathrm{J}$ Clin Pract. 2010; 13(4):379-381.

30. Pannu R, Snyder J E Waist-hip ratio is a practical and valid predictor of CAD risk ACP Journal Club. 2008 Jan-Feb;148: A9. doi:10.7326/ACPJC-2008-148-1-A09

31. National Heart Lung and Blood Institute: clinical guidelines on the identification, evaluation and treatment of overweight and obesity in adults. The Evidence Report. 2009.

32. Cash T. User's manual for the Multidimensional Body-Self Relations Questionnaire. Norfolk, VA: Old Dominion University; 2000. 33. Ogwumike OO, Adeniyi AF, Orogbemi OO. Musculoskeletal pain among postmenopausal women in Nigeria: association with overall and central obesity. Hong Kong Physiotherapy Journal. 2016; 34: 41-46

34. Dugan SA, Powell LH, Kravitz HM, Everson Rose SA, Karavolos K. Musculoskeletal pain and menopausal status. Clin J Pain. 2006; 22 (4):325-331.

35. Stevens D, Elpern E, Sharma K, Szidon P, Ankin M, Kesten S. Comparison of hallway and treadmill six-minute walk test. Am J Respir Crit Care Med. 1999; 160, 1540-1543.

36. American College of Sports Medicine. Guidelines for exercise testing and prescription. Baltimore, USA: Williams and Wilkins; 2006. 37. US Department of Health and Human Services, Public Health Service. 2002. Healthy people 2010: National Health Promotion and Disease Prevention Objectives, Washington DC. US Government Printing Office.

38. Peppa M, Koliaki C, Dimitriadis G. Body composition as an important determinant of metabolic syndrome in postmenopausal women. Endocrinol Metabol Syndrome. 2012; S1:009. doi: 10.4172/21611017.S1-009

39. Manjusha D, Madhavi K. To study the influence of structured exercise protocol on physical activity in perimenopausal women. Int J Physiother. 2014; 1(3), 152-157.

40. Poehlman ET, Tchernoff A. Traversing the menopause: changes in energy expenditure and body composition. CoronArtery Dis. 1998; 9:799-803. 